\title{
GAME-BASED LEARNING OF KNOWLEDGE REUSE IN ENGINEERING EDUCATION
}

\author{
Stenholm, Daniel; Bergsjö, Dag; Catic, Amer \\ Chalmers University of Technology
}

\begin{abstract}
This paper presents an educational game fostering a new experience-based approach to teaching knowledge transfer using a codification strategy alone. The goal is to address and highlight some common issues and challenges that occur during knowledge transfer in product development and that are often difficult for especially students to grasp through exclusively a theoretical teaching approach. The game is introduced to 60 students in the final year of their Master's curriculum. In parallel, the game has been applied in a similar setting in a comparable higher educational institution, as well as in a product development organization.

"Sometimes you win—other times you lose and learn."
\end{abstract}

Keywords: Knowledge management, Collaborative design, Game-based learning, Education, Knowledge transfer

\section{Contact:}

Stenholm, Daniel

Chalmers University of Technology

Industrial and Materials Science

Sweden

daniel.stenholm@chalmers.se 


\section{INTRODUCTION}

Knowledge Management (KM) has gained importance within engineering education and at Chalmers University of Technology, this is evident in the "Product Lifecycle Management" course. The main goal is to teach students about the importance and potential benefit of KM for overall design efficiency. The literature defines knowledge as a "justified true belief" that "increase an entity's capacity for effective actions" and KM focus on increasing the flow of knowledge in order to maximize accessibility and availability (Nonaka and Takeuchi 1995; Alavi and Leidner 2001). Although the basic concepts of KM make sense to most engineering students, it remains a challenge to have students gaining a deeper understanding of the applicability of the concepts and the potential issues concerning inferior KM for their professional future. The course evaluations written by students have repeatedly shown a common problem: students perceive the topic difficult to apply and do not think its contents will be of much added value to them as professionals.

With this background, we present in this paper a new educational game stimulating an experiencebased approach to teach knowledge transfer by applying a codification strategy to a fairly simple design/configuration problem represented by installing a powertrain for a Lego car platform.

Educational games have been a common practice in engineering education for around half a century and several reasons are behind such utilization. One is that games address specific topics that are difficult to teach to students effectively in a purely theoretical setting as students need to have relevant experience to fully understand the behaviours involved in managing product development. For students with some industrial experience, games serve as confrontation mechanisms that can make them aware of their limitations by allowing them to experience the challenges dealt with by a given practice. Doing so also aids instructors in having students understand the mapping between challenges, learning objectives and themes covered in the overall course.

This paper is largely motivated by the practical experience of the authors in teaching KM to students within the Engineering Master's program. The rationale of the approach is that students need to experience the challenges of knowledge sharing in a practical setting in order to be able to learn approaches to solving them, especially the conflict between finishing product design, test and deployment in relation to documenting experiences and knowledge for future reuse. In the context of the game presented in this paper, an introduction of a four-hour lecture is provided, involving students' own reflections and discussions, and a theoretical introduction to the KM topic.

The paper is further organized into six additional sections. Section 2 presents an introduction and taxonomy of educational games. Section 3 presents the proposed and applied educational game whereas Section 4 presents and analyses the results. Section 5 provides a reflection from two comparison cases where the game has been applied in a similar setting within another university in Norway, as well as in a product development organization. Finally, Section 6 presents our conclusion and recommendations.

\section{EDUCATIONAL GAMES}

Educational games are explicitly designed or used for educational purposes. Such games can take a variety of forms from card games to board and digital games. They contribute to the acquisition of knowledge or skills at every stage of life (childhood, student life and professional life). Their usage is frequent as they can provide enjoyment, passionate involvement, structure, motivation, ego gratification, adrenaline, creativity, emotion and social interaction during the game itself while learning takes place (Prensky 2003). These games are already widely used in the specific field of design and innovation (Braghirolli et al., 2016). A game in a learning context can be described as "a game is a system in which players engage in an abstract challenge, defined by interactivity rules and feedback resulting in a quantifiable outcome that often elicits an emotional reaction" (Kapp 2012).

Research has showed that games are able to promote meaningful learning by providing students with adaptive challenge, curiosity, self-expression, discovery, immediate feedback, clear goals, player control, immersion, collaboration, competition, variable rewards and low-stakes failure (Qian and Clark 2016). All game design elements align well with established learning theories, such as social constructivism. Therefore, these types of games can provide situated learning, promote social interactions, increase motivation and engagement and provide opportunities to develop valued $21 \mathrm{st}$ century skills, such as collaboration, creativity, communication and critical thinking (Qian and Clark 2016). 


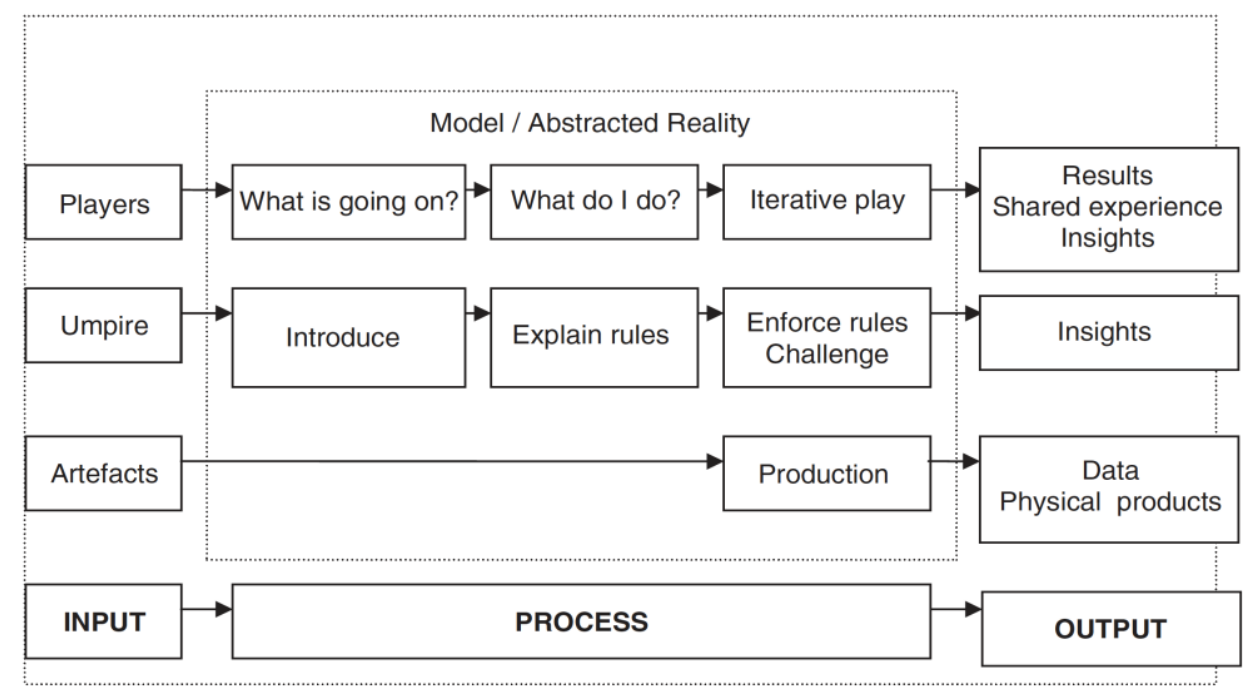

Figure 1. Framework for learning games (Lewis and Maylor 2007).

Most researchers agree that an important role in current learning structures is played by "collaborative learning", which allows participants to exchange information, as well as to producing ideas, simplifying problems and resolving tasks (Pivec et al., 2003). In this model, the teacher is the active partner, moderator and advisor of the educational process, not just a repository of the information exporting his or her own knowledge to a passive student, as was common in traditional education. This approach follows social constructivism and guides the design of effective learning environments (Pivec et al., 2003). Students bring their prior skills and knowledge to the class community. The trainer structures learning situations in which each learner can interact with other students to develop new knowledge and tailor their own needs and capacities to the task. Knowledge is generated from experience with complex tasks rather than from isolated activities, such as learning and practicing separately. Skills and knowledge are best acquired within a practical and applied context so that students are taught to easily transfer learning from classroom to "real life" and back or from one subject to another. Therefore, this method requires trainers and students to play non-traditional roles, such as interacting and collaborating with each other within the educational process. The classroom becomes a community of collaboration for learning.

There exist several taxonomies with which to classify educational games in order to provide a quick overview for parents, teachers and companies to easily identify educational games for their children, students and employees depending on the desired purpose. One example is the G/P/S taxonomy by Djaouti et al. (2011) who propose to classify serious game into three categories:

- Gameplay determines whether the game is a "serious game" or a "serious play". A game is classified as a "serious game" if the educational objectives are clearly and explicitly stated. It is a "serious play" if the goals to be achieved by the user are blurred or non-existent.

- Purpose defines the utility function of a game. It can be to broadcast a message, improve cognitive performance or encourage people to exchange data.

- Scope concerns the market targeted by the game (healthcare, ecology, culture and the arts or politics) and the public targeted (students, professionals or the general public).

The game presented in this paper was developed by applying the educational design framework proposed by Lewis and Maylor (2007), illustrating the game as a process with inputs and outputs. This model, shown in Figure 1, points out that educational games should include:

1. An input set consisting of a description of the role of the players, the role of the umpire, and the eventual devices and hardware required to play the game.

2. A process description describing initial conditions, phases and rules of the game.

3. An output set describing the expected results of the problem-solving task associated with the game and the expected insights to be learned by the game players.

\section{GAME-BASED LEARNING OF THE CONCEPT KNOWLEDGE TRANSFER}

In this section, the game is presented through a set of subsections referring to parts of the structure presented by Lewis and Maylor (2007). Some issues have been omitted because of space constrains. 
The basic properties of the game are presented here; however, depending on different needs or restrictions, some details of the game setup can vary from time to time as discussed in Section 6.

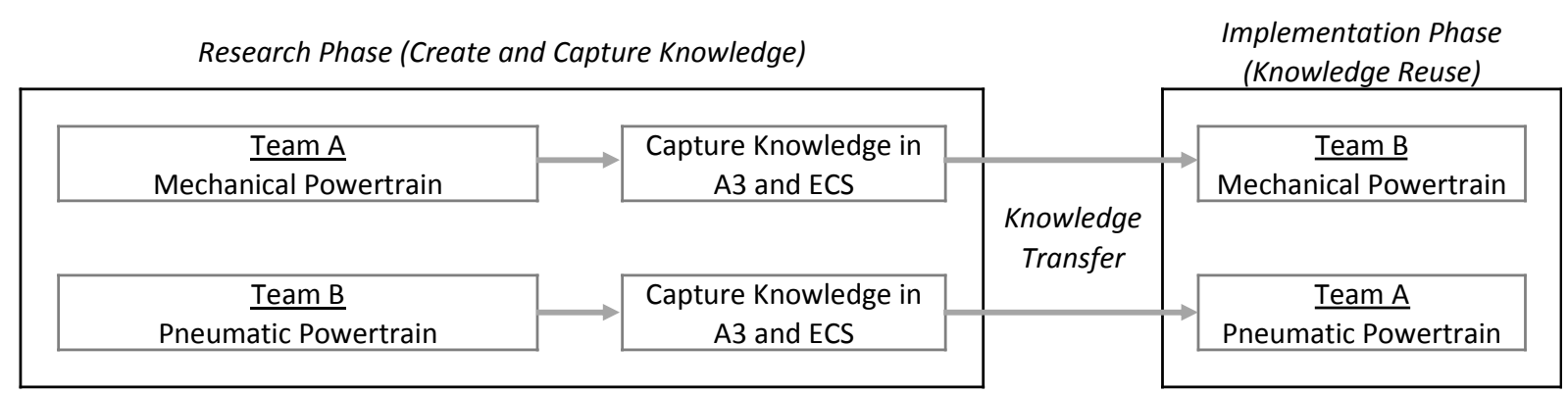

Figure 2. Description of the team configuration

\subsection{Scope and players}

The public and market targeted for the game are primarily, but not limited to, engineering students, engineers and managers in product development organizations based on the former experience of the authors in the domain. The game was further applied as part of a course package within the Product Lifecycle Management course teaching KM to 60 engineering students in their final year of their Master's program at the Chalmers University of Technology.

\subsection{Gameplay and purpose - learning objectives}

The learning objectives of this game are twofold. First, the game seeks to enable players to undergo a design process, including hypothesis creation, testing and verification. Secondly, the players explore the process of identifying, capturing, sharing and reusing lessons learned through solely a codification strategy. The game confronts them with real-life complex situations and challenges with knowledge transfer, thus increasing their understanding of KM in the context of Product Development.

\subsection{Game description}

The exercise is conducted based on a fictitious company named ZEVO AB which works towards fossil- free zero emission vehicles. ZEVO AB works with two different powertrains: pneumatic and mechanical. Players are divided into multiple groups consisting of five to seven individuals. Each group is divided into two teams, Team A and Team B. Each team initially works with either the mechanical powertrain (rubber-band) or pneumatic powertrain (balloon) (Figure 2). The overall aim of this exercise is to create and capture reusable knowledge, as well as transferring that knowledge in order to for the other team to reuse it. During the research phase, Team A sets out to create and capture knowledge regarding the mechanical powertrain based on experiments while Team B does the same for the pneumatic powertrain. The players are provided with directions on how to create, capture and reuse knowledge systematically in a structured way. In the implementation phase, Team A acquires and applies the knowledge from the ECS (which had been created and captured by Team B during the research phase) to implement the pneumatic powertrain, and vice versa. Both teams are supposed to reuse and improve existing knowledge during the implementation phase in order to maximize operating performance measured by the range driven by the vehicle.

\subsubsection{Artifacts}

The capture and reuse of knowledge are supported by two simplified KM tools: A3 problem-solving reports and Engineering Checksheets (ECS). "A3-reports" originally refer to Toyota's form to communicate complex information and solve problems, which are commonly created on a single sheet of paper (Morgan and Liker 2006; Sobek II and Smalley 2011). ECS refers to a systematic approach for capturing actionable knowledge in order to guide design decisions (Stenholm 2018). No digital means are provided and templates are printed out and provided on paper.

- A3: Works as test reports and helps structure the problem-solving process and simultaneously documents findings in a visual and condensed format. Each A3 is structured into five boxes including: 1) Background - Why is this test important \& hypothesis, 2) Describe what was tested, 3) What is the outcome - Your observation, data $\&$ information, 4) What did you learn from the 
test, and finally, 5) Recommendation for future reuse. Furthermore, each A3 consists of Title and Group Number.

- ECS: A structured approach to divide and capture design guidelines into actionable pieces of knowledge referred to as Knowledge Elements. Each Knowledge Element consists of KnowWhat (what to do), Know-How (how to do it) and Know-Why (why it is needed); see Figure 3.

Artifacts that are used as input to the game beyond the introduction material presented as a design brief to players and KM tools (Figure 4b) include: pre-built vehicles (Figure 4a), rubber bands, balloons, scissors, pens, tape, straws and additional papers. The idea is that players should have "limitless" resources of the artifacts mentioned to perform experiments.

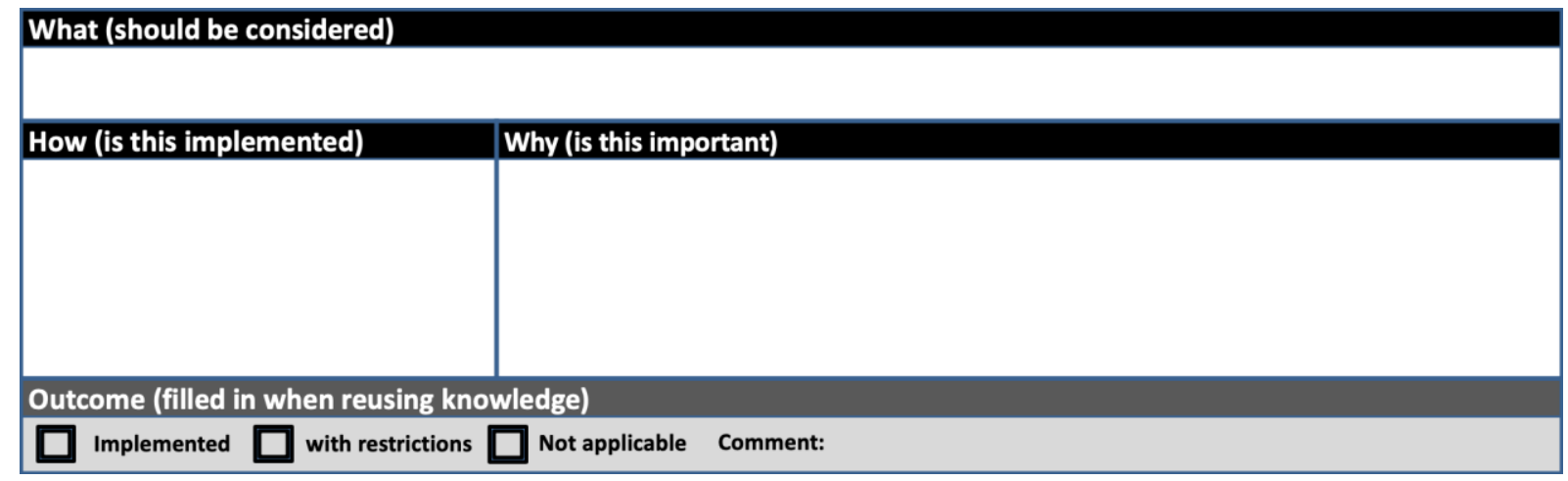

Figure 3. Template for a knowledge element within the engineering checksheet
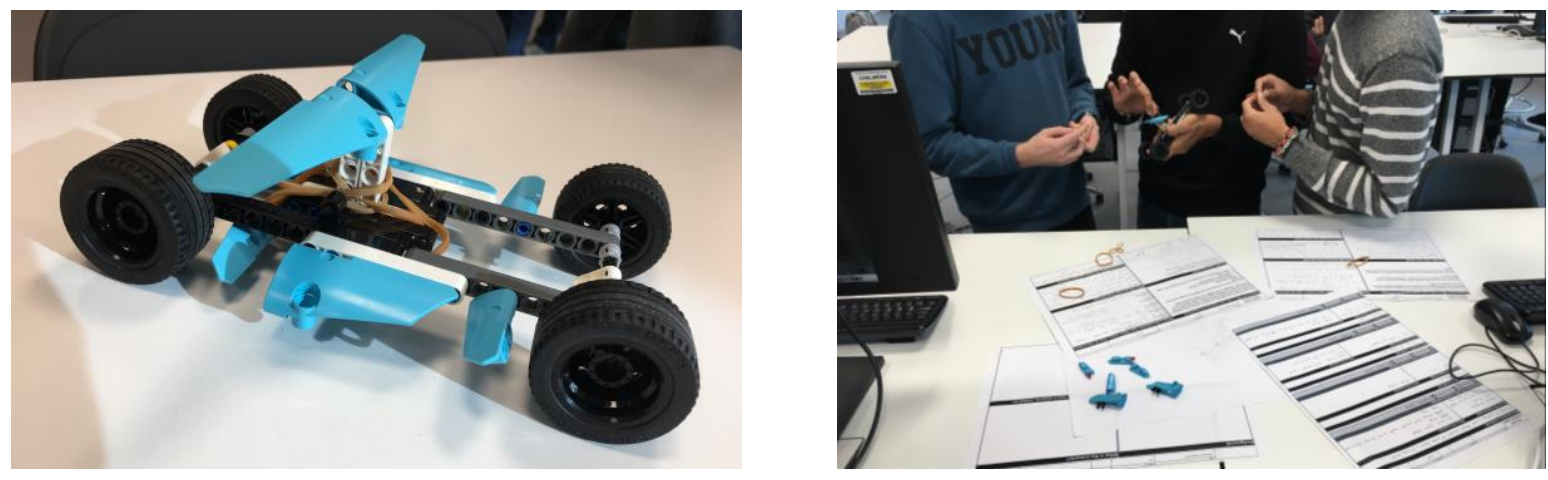

Figure 4. (a) Pre-built vehicle \& (b) A3 and ECS used during testing to capture knowledge

\subsubsection{Players}

The team should assign different roles to individuals within the team, mainly related to the KM process. The first role is responsible for capturing the hypothesis, process and findings of each experiment in the A3 format. The second role is similar except for the ECS where design guidelines/recommendations are captured. The third and final role is to be responsible for all full-scale testing within the set of rules.

\subsubsection{Process}

The total time allotted for the game is four hours divided into four phases: Introduction, Research, Implementation and Race/Evaluation.

During the first 45 minutes, the players are introduced to the purpose of the game along with timerelated setup, space-related setup, roles, rules and inputs in the form of artifacts to be used.

The research phase (Figure 5a) lasts for 90 minutes and in the first 20 minutes, the players are not allowed to touch any materials but only discuss what they see and identify hypotheses on which they want to base and perform their experiments. Some guidance is provided to the players in order to initiate the process of experiments, such as for the pneumatic powertrain experiments: "We need to identify which straw that offers best long-term propulsion for the unit. We do believe that the surface area of the straw affects how much air that is released from the balloon and this will result in either short term power (higher initial speed) or a longer release of energy but may have a larger impact 
from wheel friction. We want to test how the surface area of the straw affects the range of the vehicle".

- $\quad$ "Test 3 types of straws with different surface areas.

- Document range.

- Make a recommendation and try to explain which parameters that are affected. Focus on power, time friction and overall range".

The implementation phase lasts for 45 minutes which is shorter than the research phase to stimulate knowledge reuse in order to save time. Similar to the research phase, the players are not allowed to implement any design during the first 15 minutes but should rather focus on reading and acquiring the documented knowledge from the other team in order to plan their implementation process.

Finally, the Race/Evaluation (Figure 5b) is performed during 40 minutes followed by 20 minutes of reflection and summary. Each team performs two rounds of racing with the powertrain designs installed from reusing knowledge in the implementation phase and the final scores summarized on group level.

In the introduction, players are presented with the rules of the game. The teams compete on a group level so the overall aim is to collaborate as much as possible within each group to reach top performance. It is permissible to help other people with different roles within the team but not between teams. Knowledge transfer between teams within each group are only supposed to be performed through a codification strategy with support of the A3 and ECS templates provided and only performed once when teams exchange knowledge assets. The test rig during the research and implementation phase is not full- scale, thus bringing some limitations on testing possibilities. The only material that is allowed to be used is provided by teachers.
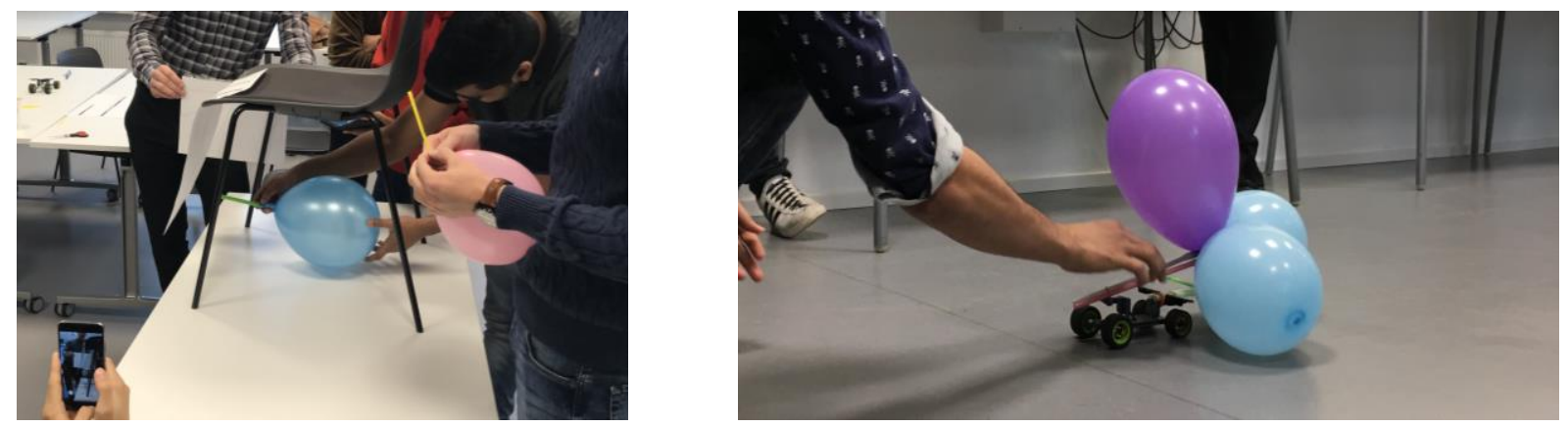

Figure 5. (a) innovative test-rig from one of the teams for measuring the properties of different balloon settings during the research phase, (b) one of the solutions during the race/evaluation phase, consisting of three balloons each connected to a straw and mounted on a vehicle.

\section{RESULTS}

In this section, the results of the game are presented. The results are gathered from multiple sources, (1) observations made by umpires who are the authors of this paper, (2) reflection by students within the Race/Evaluation phase, (3) physical products created in the form of KM documents, (4) written feedback handed in anonymously by each student as part of the final exam in the course, and finally, (5) an anonymous course evaluation.

While the game was running the umpires were present in order to answer questions, enforce rules but also to observe. Example of observations:

- Two out of four members of Team B initially viewed the knowledge transfer documents as containing everything necessary to know in order to build the vehicle. After a couple of minutes, they felt that they had completed the game and it took some time before they realized that it was only the introduction and that they where supposed to improve the configuration further.

- Some groups faced difficulties of understanding the content. A Team A member wrote "use two rubber bands - one winding the front, another winding the back". Team B initially interpreted it to be stretched with only one winding (turn) against the axle. However, after a while they concluded that the previous team actually meant "one rubber band used from the central point embracing the front axle and another from the central point embracing the rear axle in order to create four-wheel drive - not limited to one turn/winding around each axle". 
- $\quad$ Based on the umpires observations there was major variation between different student groups regarding how much effort they put into reading and understanding the content of the A3s and ECS. In some groups, students just briefly skimmed through the findings of the other group and then little or no communication between members took place, whereas other groups intensely elaborated on the knowledge captured and was curious about finding out more information.

After the Race/Evaluation, students highlighted the following issues:

- Definitely experienced the issues with knowledge transfer. Many times it was not clear what the recommendation included and what it was based on. Multiple students highlighted the benefit it would bring them if they were allowed to ask their colleagues in the other team for advice.

- Difficult to understand "when you write something, it is obvious for you - however, when you read something, it makes more or less or even no sense because some important aspects are missing". One student expressed that "writing is not possible" in relation to the fact that they had trouble transferring the knowledge.

- One group stressed that they felt a little restricted to the ECS provided from the other group. They did not trust the content but followed it anyway and after a while it became obvious that the guidelines were not accurate.

Findings found by examining the A3's and ECS's created:

- No groups captured knowledge about the actual running of the car in the Race/Evaluation phase, for example what to consider when releasing the car in order to achieve top performance.

- The teams that performed best received a higher amount of Knowledge Elements of good quality. For a Knowledge Element to be seen as qualified, it would need to consist of a clear action, be based on findings and include a guide on how to implement it (Figure 6). Only three out of 41 Knowledge Elements were disqualified.

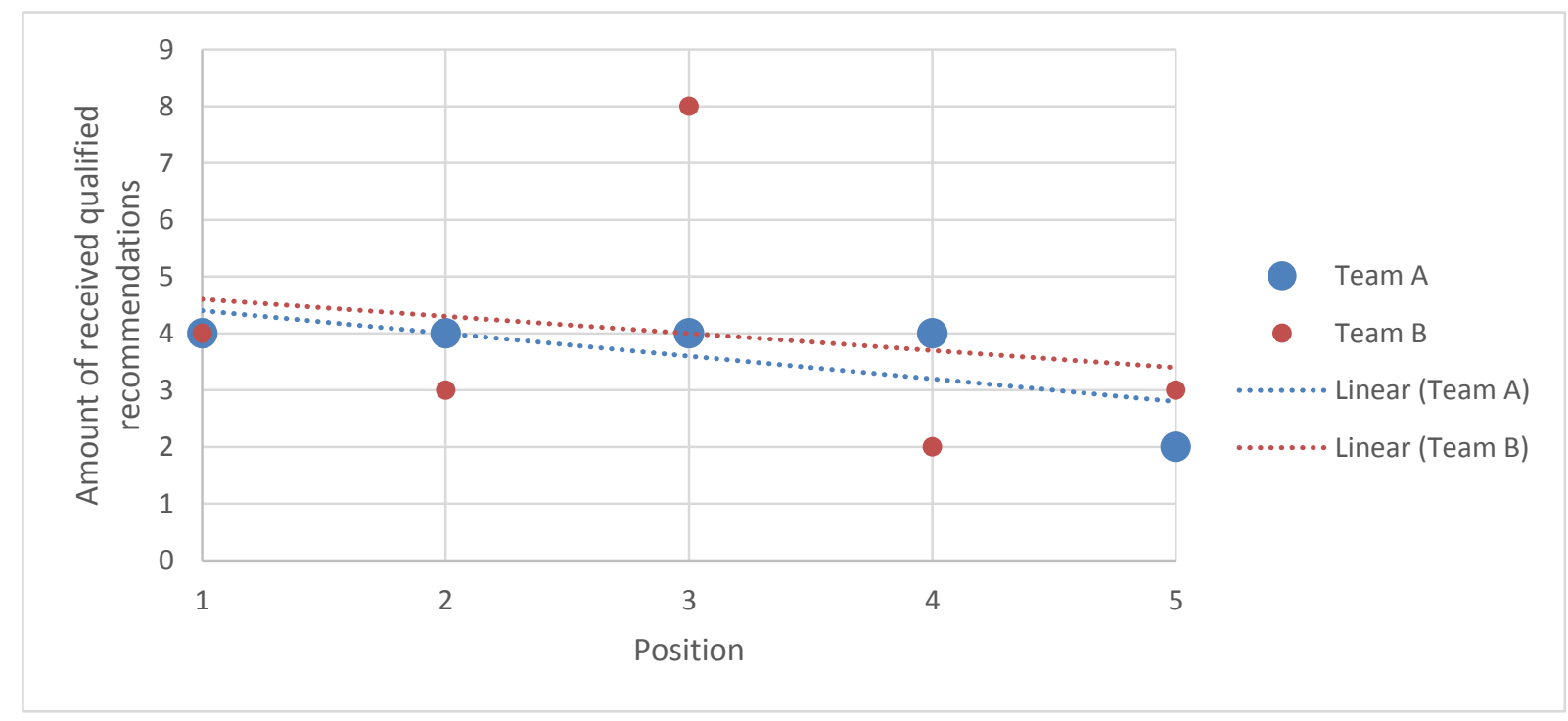

Figure 6. Team positions mapped against the amount of qualified recommendations received.

The feedback on the final exam reflected $23 \%$ of the total score (5 of 22) with the question: "Give a reflection on the in-class the Knowledge Management (KM) exercise. What was your role? How was KM applied? What barriers to knowledge transfer did you experience, and how did they affect the actual outcome? How could you have worked within the established rules to have been able to transfer/reuse knowledge more effectively? (max 600 words)". The students achieved one score for explaining their role and what they had accomplished during the game, another for reflecting on the process of capturing knowledge, a third for reflecting on the reuse of knowledge and a fourth score for their reflections of the overall lessons learned. The final score was earned if the reflection had been performed exceptionally well and in depth with a focus on KM (Figure 7 provides a graph over the distribution of points). Findings from the question on the home exam:

- The misalignment between the expectations that the team capturing the knowledge had on the team who were supposed to reuse knowledge and the actual need for knowledge of the reusing 
team. "The main barrier was that the we didn't know what information that the other group would think is most important and which information that was unnecessary. Since they couldn't email or call us to get supporting information, we felt that the most important documentation should be about the final design and about which designs that worked. This was a problem since the other group wanted to do tests on their own designs. This resulted in that they performed tests that we knew would not work which resulted in the other group using a design that we knew wouldn't work in the competition".

- Multiple students focused too much on the game and the end result in the form of the vehicle performance and missed out on the learning objective, including the KM perspective.

- Trust in the documented knowledge was one of the most commonly mentioned barriers for reuse of the knowledge which resulted in duplicitous and unnecessary tests.

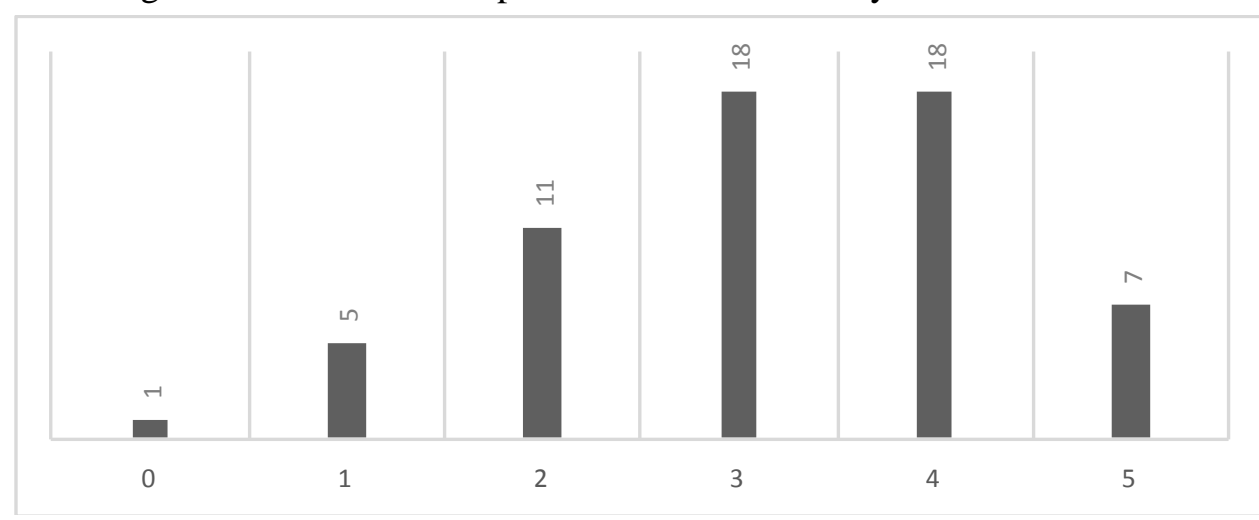

Figure 7. Distribution of score on the home exam question regarding the exercise between the 60 students.

The course concluded with an anonymous evaluation which elicited answers from 36 respondents. No negative comments were submitted about the KM game and wherever mentioned, it was only in a positive way. On the question of how group roles and cooperation between students had worked, a student wrote "The workshop with the balloon cars.... that was actually really nice. it was fun and one really understood the importanceldifficulty in transferring knowledge between groups. Nothing to complain here". On the question if there was something that should be kept for the next round of this course, eleven students replied with different activities and $45 \%$ of them singled out the KM game ("The KM exercise was really good and it should be retained", "The exercise within KM was also nice", "Knowledge exercise", "...the workshop with the balloon cars..." and "The KM workshop"), whereas on the question of whether something should be changed for the next round, no students mentioned the KM game.

\section{REFLECTIONS FROM COMPARISON CASES}

The game has in parallel been tested in various settings involving industrial practitioners, Master's students from other universities and PhD students. Two of these cases are discussed below to provide insights and perspectives on the game. In this section, teachers reflect on each of the two cases based on observations and brief analyses of the knowledge assets produced, as well as on verbal reflections performed after each case.

\subsection{Game conducted with 20 systems engineering master students at USN in norway}

The execution of this game followed the identical initial setting where the original game was performed. However, due to fewer participants and the overall greater understanding of the industrial context by students (many of them employed in industry half-time), the observations would be quite different. Just like in the primary case described in this paper, the students were given the same task to reflect on their experience, in addition to a home assignment task.

Since the students had some practical knowledge of how knowledge transfer works in complex organizations, there was initially a larger focus on the documentation and the teacher experienced that the students were not that quick in getting started with their experiments. There were discussions going on regarding alternative approaches and the division of work among team members. Some 
students in the teams also had experience of specific technology transfer projects similar to the exercise at hand.

\subsection{Game in an industry setting}

As part of an industrial innovation project (Ingreppi), the game was run with an engineering management team at GKN Aerospace. The group consisted of eight managers (levels 2 and 3) within the GKN product development organization. The time allowed for the different game phases was shortened and due to the limited number of participants only two teams were created. Since there were not enough participants present to divide them into four teams and run a competition, the target was on improving the vehicle driving range between the two teams. The range of the first team's prototype was measured and then the second team was to improve on that range, using both the previous team's solution and the knowledge documentation. This gave the game a different twist, but a similar amount of learning was achieved. However, the lack of a competitive dimension gave the exercise a different focus.

However, the main outcome of running the game at GKN Aerospace was that even engineering managers involved in daily knowledge exchange and transfer in the workplace found the exercise useful and relevant. They gained similar experiences as students did when it came to omitting the perspective of the knowledge reuser and focusing a little too much on quantity rather than quality of experiments.

"We fell straight into the pitfall of not trusting the content we received from the other group and started redoing all the tests until we came to the conclusion that the first group was correct and the knowledge was accurate" - Head of an engineering group.

The group of practitioners identified several similarities between the game and real-world technology development. An example is the importance of conducting experiments in a relevant, real-world setting. The team, tasked with developing knowledge regarding the rubber band powertrain, conducted all of their experiments on the table in the conference room which (in hindsight) offered a lot more traction than the linoleum floor where the full-scale measurements was later performed. This led to tests being performed in an environment that was not relevant and that much of their knowledge was wasted. This was shown when the car experienced a lot of wheel spin when the real tests were performed compared to a conference table.

A concluding remark regarding running the game in an industrial setting is that the same principles apply to both Master's students and experienced engineers. This finding validates the basic principles regarding the difficulty to capturing and sharing knowledge in a reusable format, but also in both cases highlights the importance of focusing on the knowledge reuser. In relation to the game structure, it was found that a shorter introduction to the game was feasible in the industrial setting (only one hour of total introduction compared to four hours for the students). This is basically attributed to the previous knowledge and experience of the engineers, including a quicker understanding of the subject and the possibility of applying what is taught to actual experience.

\subsection{Variation of the game}

Variations of the game. To evolve the game, several minor changes have been introduced in order to maximize the lessons learned and focus on the relevant issues, i.e. knowledge reuse and how to document knowledge for future reuse. The following variations have been tested:

1. When the number of participants is too small to have two competing groups (with two teams in each group, one conducting the research and another performing the implementation), it is possible to run the game as a single group or with potentially 2-5 participants in each team. The teams could be competing against the "record" of other teams achieved in previous runs of the game. Or as described in the "industry setting" scenario above, they can work on continuous improvements focusing on the results of the previous team, being able to reuse both the product, knowledge documentation and the documented results of their full-scale testing. There is another dynamic in the groups as they are completely set up to build on each other's results, thereby removing the competitive edge and adding a collaborative part.

2. In most settings where the game has been run, there has been no known benchmark to compete against. As a result, some participants end up thinking that 4-6 meters is a good result. However, when the same groups were given a benchmark result such as "it is possible to run 16 meters with the car you have in your hands", the immediate tests results increased to 10-12 meters as the source of the problem was identified, e.g. in a specific case, there was an unintentional friction caused by squeezing the wheels of the car tightly together with the drive axis. When informed 
about the longer potential distance, the team started identifying root causes for the short roll after the power from the rubber bands diminished. After a few tests, the root cause was identified, the wheels on the axis untightened and the car travelled twice the initial distance. There are benefits and disadvantages to giving a benchmark to participants. However, when a group is apparently struggling or seem to be satisfied with a short travelling distance, the benchmark length is normally mentioned by the tutor to challenge the group to think outside the box.

\section{CONCLUSION}

The objective of this paper is to present a new way of teaching knowledge transfer through the use of a collaborative game. We first presented some earlier research on the topic of educational games and a few existing taxonomies. After showing the benefits of using collaborative games for educational purposes, we used the taxonomies presented to structure and provide a brief overview of the game along with its objective of providing an experience-based approach to teach KM and knowledge transfer with solely a codification strategy in product development. The game consists of multiple artifacts, e.g. a prebuilt vehicle and two KM tools, A3 and ECS, a well-structured process and a set of rules to be followed.

Through the analysis of the written reflections by students, artifacts created during game playing and the observations of umpires, the game has shown to provide the students with the possibility of experiencing challenges and issues that often are present during knowledge transfer beyond their theoretical understanding of the subject.

The application of the game in various settings provides indication of its value outside a university setting. We believe that this study will help understand the challenges that come along with knowledge transfer and knowledge reuse both when teaching students the subject, as well as in the interaction with professionals who seek to achieve improved knowledge transfer and reuse in their daily work.

\section{REFERENCES}

Alavi, M. and Leidner, D.E. (2001). "Review: Knowledge management and knowledge management systems: Conceptual foundations and research issues", MIS quarterly, Vol. 25 No. 1, pp. 107-136.

Braghirolli, L.F., Ribeiro, J.L.D., Weise, A.D. and Pizzolato, M. (2016). "Benefits of educational games as an introductory activity in industrial engineering education", Computers in Human Behavior, Vol. 58, pp. 315324, available: http://dx.doi.org/10.1016/j.chb.2015.12.063.

Djaouti, D., Alvarez, J. and Jessel, J.-P. (2011). "Classifying serious games: the G/P/S model', in Handbook of research on improving learning and motivation through educational games: Multidisciplinary approaches", IGI Global, pp. 118-136, available: http://dx.doi.org/10.4018/978-1-60960-495-0.ch006.

Kapp, K.M. (2012). The gamification of learning and instruction: game-based methods and strategies for training and education, John Wiley \& Sons.

Lewis, M.A. and Maylor, H.R. (2007). “Game playing and operations management education”, International Journal of Production Economics, Vol. 105 No. 1, pp. 134-149, available: http://dx.doi.org/10.1016/j.ijpe.2006.02.009.

Morgan, J.M. and Liker, J.K. (2006). The Toyota product development system, Seattle, WA: Productivity Press.

Nonaka, I. and Takeuchi, H. (1995). The knowledge-creating company: How Japanese companies create the dynamics of innovation, Oxford university press.

Pivec, M., Dziabenko, O. and Schinnerl, I. (2003) “Aspects of game-based learning', in 3rd International Conference on Knowledge Management, Graz”, Austria, pp. 216-225.

Prensky, M. (2003). "Digital game-based learning", Computers in Entertainment (CIE), Vol. 1 No. 1, pp. 21-21, available: http://dx.doi.org/10.1145/950566.950596.

Qian, M. and Clark, K.R. (2016). "Game-based Learning and 21st century skills: A review of recent research", Computers in Human Behavior, Vol. 63, pp. 50-58, available: http://dx.doi.org/10.1016/j.chb.2016.05.023.

Sobek II, D.K. and Smalley, A. (2011). Understanding A3 thinking: a critical component of Toyota's PDCA management system, Boca Raton: CRC Press.

Stenholm, D. (2018). Reuse of Engineering Knowledge: Perspectives on Experience-Based Codified Knowledge in Incremental Product Development, Sweden: Chalmers University of Technology.

\section{ACKNOWLEDGMENTS}

The financial support of the Swedish Governmental Agency for Innovation System (Vinnova) is greatly acknowledged. This study was conducted within the Vinnova Vinnex Excellence Centre for Product Realization and the Production Area of Advance at the Chalmers University of Technology. 